\title{
CARDIOPULMONARY BYPASS IS ASSOCIATED WITH EARLY ALLOGRAFT DYSFUNCTION BUT NOT DEATH AFTER DOUBLE-LUNG TRANSPLANTATION
}

\author{
James S. Gammie, MD \\ Jung Cheul Lee, MD \\ Si M. Pham, MD \\ Robert J. Keenan, MD \\ Robert J. Weyant, DMD, PhD \\ Brack G. Hattler, MD \\ Bartley P. Griffith, MD
}

\begin{abstract}
Objectives: To assess the effect of cardiopulmonary bypass on allograft function and recipient survival in double-lung transplantation. Methods: Retrospective review of 94 double-lung transplantations. Results: Cardiopulmonary bypass was used in 37 patients (CPB); 57 transplantations were accomplished without bypass (no-CPB). Bypass was routinely used for patients with pulmonary hypertension $(n=27)$ and for two recipients undergoing en bloc transplantation. Cardiopulmonary bypass was required in eight $(12.3 \%)$ of the remaining 65 patients. Mean ischemic time was longer in the CPB group (346 vs 315 minutes, $p=0.04$ ). The CPB group required more perioperative blood (11.4 vs 6.0 units, $p=0.01)$. Allograft function, assessed by the arterial/alveolar oxygen tension ratio, was better in the no-CPB group at 12 and 24 hours after operation (0.54 vs 0.39 at 12 hours, $p=0.002$; and 0.63 vs 0.38 at 24 hours, $p=0.001$ ). The CPB group had more severe pulmonary infiltrates at both 1 and 24 hours $(p=0.005)$. Diffuse alveolar damage was more common in the CPB group (69\% vs 35\%, $p=0.002)$. Median duration of intubation was longer in the CPB group (10 days) than in the no-CPB group ( 2 days, $p=0.002$ ). The 30-day mortality rate $(13.5 \%$ vs $7.0 \%$ in the $\mathrm{CPB}$ and no-CPB groups) and 1-year survival (65\% vs 67\%, CPB and no-CPB) were not significantly different. Conclusions: In the absence of pulmonary hypertension, cardiopulmonary bypass is only occasionally necessary in double-lung transplantation. Bypass is associated with substantial early allograft dysfunction after transplantation. (J Thorac Cardiovasc Surg 1998;115:990-7)
\end{abstract}

L ung transplantation for individuals with endstage pulmonary disease was first performed successfully in the context of heart-lung transplantation. ${ }^{1}$ Pressures to maximally use scarce donor organs stimulated increased application of isolated lung transplantation. ${ }^{2}$ On the basis of experience with heart-lung transplantation, double-lung transplantation was initially performed en bloc, with anastomosis of the airway at the tracheal bifurcation

From the Division of Cardiothoracic Surgery, The University of Pittsburgh Medical Center, Pittsburgh, Pa.

Read at the Twenty-second Annual Meeting of The Western Thoracic Surgical Association, Maui, Hawaii, June 26-29, 1996.

Received for publication March 10, 1997; revisions requested May 21, 1997; revisions received Dec. 11, 1997; accepted for publication Dec. 11, 1997.

Address for reprints: James S. Gammie, MD, University of Pittsburgh, Division of Cardiothoracic Surgery, C-700 Scaife, 200 Lothrop St., Pittsburgh, PA 15213.

Copyright (C) 1998 by Mosby, Inc.

$0022-5223 / 98 \$ 5.00+0 \quad \mathbf{1 2} / \mathbf{6} / \mathbf{8 8 2 1 1}$ and mandatory use of cardiopulmonary bypass (CPB). Complications related to ischemia of the bronchi and trachea around the carina prompted adoption of sequential single-lung implantation as the method of choice for double-lung transplantation. $^{3,4}$ In addition to more robust anastomoses at the bronchial level, use of CPB was no longer necessary in all cases. There is experimental ${ }^{5}$ and clinical $^{6}$ evidence that CPB contributes to allograft dysfunction after pulmonary transplantation. We reviewed our clinical experience to assess the impact of $\mathrm{CPB}$ on early allograft function and recipient survival, and to define the relative requirements and indications for bypass in double-lung transplantation.

\section{Patients and methods}

Patient population. One hundred adult (age $>15$ years) double-lung transplantations were performed on 98 patients at the University of Pittsburgh Medical Center betweeen January 1990 and July 1995. Six transplantations performed with the use of CPB were excluded, leaving 94 
Table I. Possible risk factors for prolonged posttransplantation intubation and mortality included in the multivariate analysis

Use of CPB

Recipient diagnosis

Allograft ischemic time

Year of operation

Recipient age

Recipient sex

Donor age

for analysis. Four excluded patients were receiving extracorporeal life support (ECLS) before transplantation (three retransplantations and one primary respiratory failure). The two others included a 40-year-old man with Eisenmenger's syndrome in whom severe systemic hypotension (systolic pressure $<30 \mathrm{~mm} \mathrm{Hg}$ ) developed before initiation of CPB. This markedly vasodilated state persisted, and he died in the operating room. The final excluded patient was a 53-year-old man with pulmonary fibrosis who received an oversized double-lung graft that prevented primary closure of the chest. Bilateral upper lobectomies failed to prevent death from hypoxia, which occurred 8 days after the operation.

Donor selection and perioperative management. Donors were less than 60 years of age, had clear chest radiographs, were able to maintain an acceptable arterial oxygen tension $\left(\mathrm{PaO}_{2}\right.$ on an inspired oxygen fraction $\left[\mathrm{FiO}_{2}\right]$ of $100 \%$ and a positive end-expiratory pressure of 5 $\mathrm{cm} \mathrm{H}_{2} \mathrm{O}$ ), were free of infected sputum, had normal findings at bronchoscopy, and were of appropriate size match with the recipient. ${ }^{7-10}$ Pulmonary preservation was carried out with Euro-Collins solution early in the experience (through April 1991) and thereafter with University of Wisconsin solution. Alprostadil (prostaglandin $\mathrm{E}_{1}, 500$ $\mu \mathrm{g}$ ) was infused into the superior vena cava before infusion of preservation solution. Recipients underwent standard pulmonary function testing before transplantation and determination of left and right ventricular ejection fractions by noninvasive radionuclide examination. For those patients requiring $\mathrm{CPB}$, duration of bypass was recorded. Ischemic times were defined as the interval from donor crossclamping to reperfusion and were recorded for each lung. Intraoperative and postoperative hemodynamic data were obtained with an indwelling pulmonary artery catheter.

Indications for CPB. CPB was routinely used in all patients with primary or secondary pulmonary hypertension $(n=27)$ or for those patients who underwent en-bloc double-lung transplantation early in the series $(n=6)$. In all other cases, bypass was used only when hemodynamic, technical, or other intraoperative factors made it necessary.

Assessment of early allograft function. Chest radiographs were obtained at 0 and 24 hours after the operation. A semiquantitative scale was used to assess the degree of pulmonary allograft injury, with scoring as follows: 0 , no abnormal findings; 1 , perihilar infiltrate; 2 , infiltrate localized to a limited lung field; 3 , diffuse moderate interstitial and alveolar infiltrate; 4 , diffuse severe
Table II. Patient characteristics

\begin{tabular}{lccc}
\hline \multicolumn{1}{c}{ Characteristic } & $C P B$ & No-CPB & $p$ Value \\
\hline No. of patients & 37 & 57 & \\
Disease: & & & \\
$\quad$ Pulmonary hypertension & 27 & 0 & \\
$\quad$ Cystic fibrosis & 3 & 38 & \\
$\quad$ Chronic obstructive pul- & 1 & 12 & \\
$\quad$ monary disease & & & \\
$\quad$ Bronchiectasis & 3 & 6 & \\
$\quad$ Pulmonary fibrosis & 1 & 1 & \\
$\quad$ Other & 2 & 0 & \\
Age & $38 \pm 10$ & $34 \pm 11$ & 0.15 \\
Gender & & & 0.06 \\
$\quad$ Male $(\%)$ & $12(32)$ & $30(53)$ & \\
$\quad$ Female $(\%)$ & $25(68)$ & $27(47)$ & \\
FEV $(\%$ predicted $)$ & $66 \pm 26$ & $22 \pm 7$ & 0.001 \\
FVC $(\%$ predicted $)$ & $75 \pm 21$ & $42 \pm 15$ & 0.001 \\
DLCO $(\%)$ & $68 \pm 27$ & $53 \pm 21$ & 0.01 \\
RVEF $(\%)$ & $32 \pm 15$ & $43 \pm 9$ & 0.001 \\
LVEF $(\%)$ & $63 \pm 13$ & $64 \pm 9$ & 0.83 \\
Donor PaO Pio $_{2}(\mathrm{~mm} \mathrm{Hg})$ & $464 \pm 89$ & $497 \pm 78$ & 0.14 \\
Donor age & $28 \pm 13$ & $27 \pm 12$ & 0.45 \\
\hline
\end{tabular}

$F E V_{l}$, Forced expiratory volume in 1 second; $F V C$, forced vital capacity; $D L C O$, diffusing capacity of carbon monoxide; $R V E F$, right ventricular ejection fraction; $L V E F$, left ventricular ejection fraction.

interstitial and alveolar infiltrate. Each lung was graded independently and a mean score was calculated. Arterial blood gases were obtained at multiple intervals after transplantation and used to calculate the arterial/alveolar oxygen tension ratio $\left(\mathrm{a} / \mathrm{A} \mathrm{O}_{2}\right.$ ratio) and the $\mathrm{PaO}_{2} / \mathrm{FiO}_{2}$ ratio. The alveolar oxygen tension $\left(\mathrm{PAO}_{2}\right)$ was calculated as follows: $\mathrm{PAO}_{2}=\left(760-\mathrm{P}_{\mathrm{H} 2 \mathrm{O}}\right) \mathrm{FiO}_{2}-1.25 \mathrm{PaCO}_{2}$, where $\mathrm{P}_{\mathrm{H} 2 \mathrm{O}}$ is the water vapor partial pressure, assumed to be 47 $\mathrm{mm} \mathrm{Hg}$ at $37^{\circ} \mathrm{C}, \mathrm{Fio}_{2}$ is the inspired fraction of oxygen, and $\mathrm{PaCO}_{2}$ is the arterial partial pressure of carbon dioxide. ${ }^{11}$ The diagnosis of diffuse alveolar damage (DAD) was assigned based on histology from biopsy or autopsy specimens. Blood bank records were reviewed, and the number of units of packed red blood cells transfused in the 72-hour perioperative period (beginning at time of arrival in the operating room) were tabulated. Time of intubation, length of stay in the intensive care unit, and patient survival at 30 days and 1 year after transplantation were recorded.

Statistical analysis. Statistical computations were carried out with JMP software (SAS Institute, Cary, N.C.). Comparisons between patient characteristics, mean allograft ischemic times, perioperative blood transfusion requirements, a/ $\mathrm{A} \mathrm{O}_{2}$ ratios, and $\mathrm{PaO}_{2} / \mathrm{FiO}_{2}$ ratios in the two groups were carried out with the unpaired $t$ test. Comparison of mean chest radiographic scores and deaths was calculated with the $\chi^{2}$ likelihood ratio. Fisher's exact test was used to compare the need for ECLS in the two groups. The Kruskal-Wallis rank sum test was applied to assess duration of intubation and length of stay in the intensive care unit. Multiple logistic regression analysis was applied to assess the effect of various donor, recipient, and perioperative variables on two measures of outcome, a requirement for prolonged intubation ( $>7$ days) and 


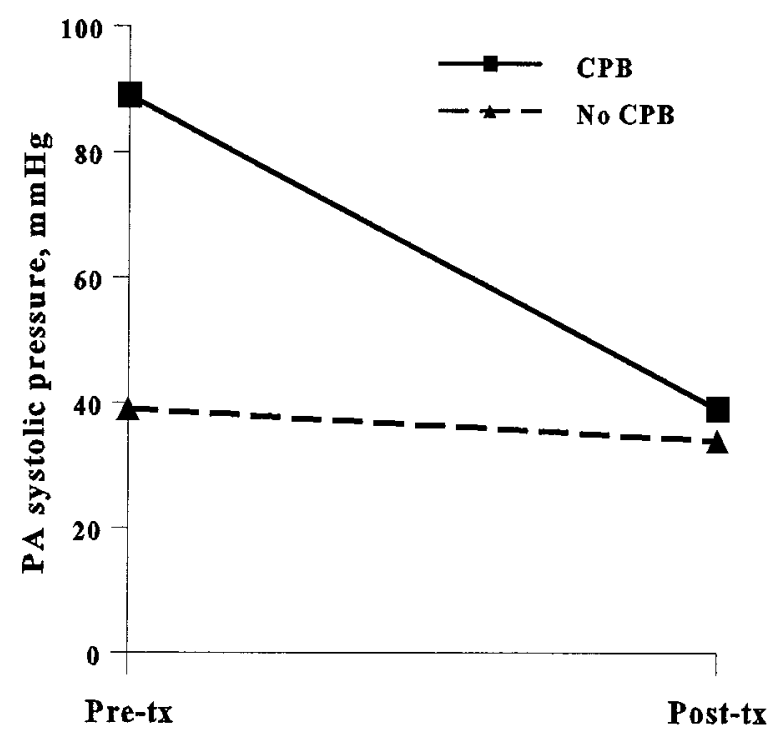

Fig. 1. Preimplantation and postimplantation hemodynamics in the $\mathrm{CPB}$ and no-CPB groups. $P A$, Pulmonary artery; $t x$, transplantation.

1-month survival. Possible risk factors affecting outcome that were included in the analysis are listed in Table I.

\section{Results}

Recipient and donor characteristics. CPB was used for 37 patients; 57 transplantations were accomplished without bypass (no-CPB). Comparison of recipient- and donor-related characteristics between the $\mathrm{CPB}$ and no-CPB groups is detailed in Table II. Mandatory use of CPB for recipients with pulmonary hypertension explains the markedly different patterns of preoperative pulmonary function tests in the two groups and the lower right ventricular ejection fraction in the CPB group. Although all patients with pulmonary hypertension underwent transplantation on bypass, use of CPB was largely avoided in other disease categories. Three of nine (33\%) patients undergoing transplantation for bronchiectasis needed CPB support, and only 3 of 41 (7\%) of those patients with cystic fibrosis needed CPB. Finally, although 1 of 13 patients with chronic obstructive pulmonary disease required $\mathrm{CPB}$, this was an en-bloc transplantation.

Indications for bypass. Indications for $\mathrm{CPB}$ are listed in Table III. Excluding transplantations for pulmonary hypertension and early en-bloc transplantations $(n=29)$, CPB was required in 8 of the remaining 65 recipients $(12.3 \%)$. The most common
Table III. Indications for $C P B$

\begin{tabular}{lc}
\hline \multicolumn{1}{c}{ Indication } & $\begin{array}{c}\text { No. of } \\
\text { patients }\end{array}$ \\
\hline $\begin{array}{l}\text { En-bloc transplantation } \\
\text { Pulmonary hypertension }\end{array}$ & 6 \\
$\begin{array}{l}\text { Hypoxemia and hypotension on one-lung ventilation } \\
\text { during initial hilar dissection, before crossclamping }\end{array}$ & 5 \\
Hypotension and right ventricular dilation after im- & 1 \\
$\quad$ plantation of first lung and crossclamping of sec- & \\
$\quad$ ond pulmonary artery & \\
Facilitate dissection (re-do) & 1 \\
Elective & 1 \\
Total & 37 \\
*In total, 27 patients with pulmonary hypertension underwent transplan- \\
tation on bypass; 4 are included in the en-bloc group.
\end{tabular}

Table IV. Graft ischemic times

\begin{tabular}{lccc}
\hline \multicolumn{1}{c}{ Graft } & $C P B^{*}$ & No-CPB & $p$ Value \\
\hline First lung & $307 \pm 67$ & $252 \pm 67$ & 0.002 \\
Second lung & $369 \pm 60$ & $378 \pm 80$ & 0.58 \\
Mean & $346 \pm 59$ & $315 \pm 72$ & 0.04 \\
\hline
\end{tabular}

*Mean ischemic time in minutes, \pm standard deviation.

scenario in which CPB was needed was during initial hilar dissection: single-lung ventilation caused hypotension and hypoxemia, which prompted initiation of bypass. In one instance CPB was used to permit safe dissection in a patient undergoing late reoperation after a heart-lung transplantation, and in another (done early in our experience) bypass was used electively. Finally, one patient required initiation of bypass after implantation of the first lung. In this case, crossclamping of the (remaining) pulmonary artery precipitated hypotension and right ventricular dilation.

Duration of CPB and allograft ischemic times. The mean duration of bypass was $240 \pm 43$ minutes. Ischemic times for the first and second implanted lungs are detailed in Table IV. The mean ischemic time for both grafts was approximately 30 minutes longer in the group requiring CPB $(p=0.04)$. Blood use in the 72-hour perioperative period was higher for the group requiring bypass (11.4 vs 6.0 units packed red blood cells, $p=0.01$ ).

Preimplantation and postimplantation hemodynamics. Mean pulmonary artery pressures measured before transplantation reflected the predominance of pulmonary hypertension in the $\mathrm{CPB}$ group (Fig. 1). Although pulmonary artery systolic pressures before transplantation were markedly higher in the CPB group ( 89 vs $39 \mathrm{~mm} \mathrm{Hg}$ ), they were similar after transplantation (39 vs 34, respectively). 


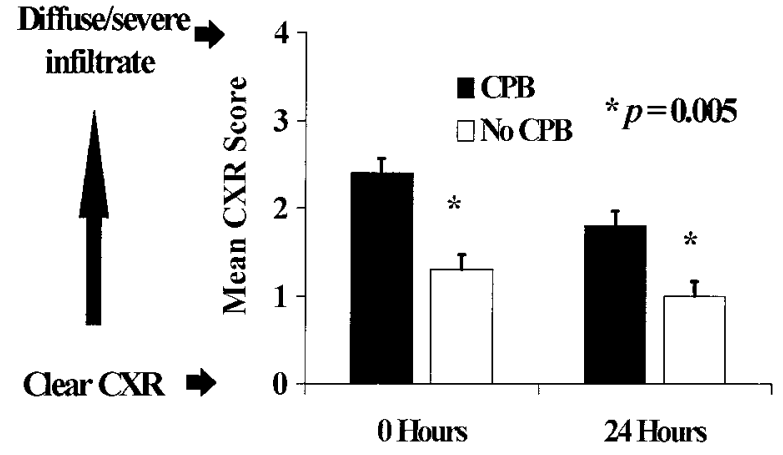

Fig. 2. Chest $x$-ray $(C X R)$ scores at 0 and 24 hours after transplantation. Values are expressed as means \pm standard error of the mean. ${ }^{*} p=0.005$

Postoperative allograft function. Mean chest $\mathrm{x}$ ray scores for both groups were compared 0 and 24 hours after transplantation. Immediately after the operation, the CPB group had a mean chest $\mathrm{x}$-ray score of $2.4 \pm 0.17$ (standard error of the mean), in comparison to $1.3 \pm 0.18$ for the group done without bypass (Fig. 2). At 24 hours, scores had improved to $1.8 \pm 0.17$ in the CPB group and $1.0 \pm 0.16$ in the no-CPB group. At both time periods, the CPB group had significantly more pronounced infiltrates than did the no-CPB group $(p=0.005)$. Fig. 3 details the $\mathrm{PO}_{2} / \mathrm{FiO}_{2}$ ratio at various intervals after operation. The arterial/alveolar oxygen tension ratio was better in the no-CPB group at 12 and 24 hours after operation ( 0.54 vs 0.39 at 12 hours, $p=0.002$; and 0.63 vs 0.38 at 24 hours, $p=0.001$ ). Both indices of oxygenation were significantly lower in the CPB group at 12 and 24 hours. Postoperative ECLS was needed in 6 of $37(16.2 \%)$ in the CPB group and in 3 of $57(5.3 \%)$ in the no-CPB group $(p=0.08)$. Histologically proven DAD was more common in the CPB group ( $69 \%$ vs $35 \%, p=0.002)$.

Median duration of intubation was markedly longer in the CPB group (10 days) than in the no-CPB group (2 days, $p=0.002$, Fig. 4). Similarly, median length of stay in the intensive care unit was almost twice as long in the CPB group as in the no-CPB group (16 and 8.5 days, respectively; $p=$ $0.05)$.

Analysis of risk factors by multiple logistic regression identified several factors associated with prolonged postoperative intubation (defined as $>7$ days, Table V). The strongest risk factor for prolonged intubation was use of CPB (odds ratio = 6.2), followed by a recipient diagnosis of bronchiectasis (odds ratio $=5.9$ ). Importantly, pulmonary

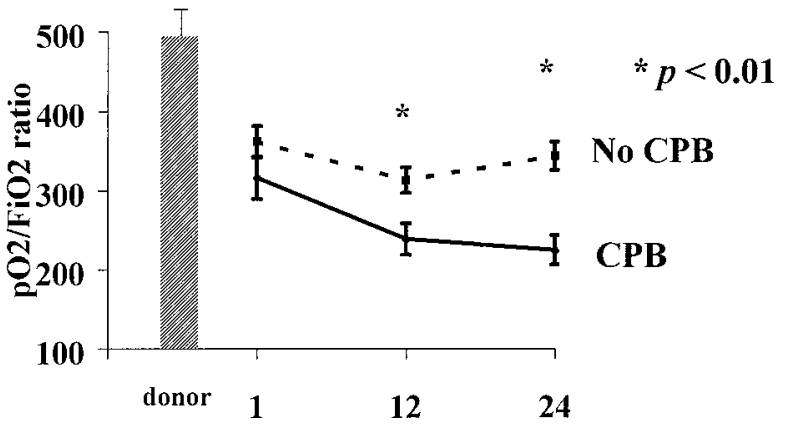

Time after transplantation (hours)

Fig. 3. Posttransplantation $\mathrm{PO}_{2} / \mathrm{FiO}_{2}$ ratios.

hypertension did not appear as an independent risk factor for prolonged ventilatory support. Increasing recipient age and earlier year of operation were also associated with a mild increased risk of prolonged intubation.

Death. The 30-day mortality rate was 5 of 37 $(13.5 \%)$ patients in the CPB group and 4 of 57 $(7.0 \%)$ patients in the no-CPB group. This difference did not reach statistical significance $(p=0.30)$. Survival at 1 year was nearly identical in the two groups: $68 \%$ in the CPB group and $67 \%$ in the no-CPB group.

Multiple regression analysis was applied to identify risk factors associated with early (1-month) death. Of all possible risk factors analyzed (Table I), none were predictive of 30-day death.

\section{Discussion}

Since the introduction of sequential single-lung transplantation, CPB is no longer mandatory for double-lung transplantation. Although it seems intuitive that CPB, which is known to produce a "whole-body" inflammatory response ${ }^{12-14}$ and requires full systemic anticoagulation, would have a negative impact on the function of a newly implanted pulmonary allograft, there remains controversy over the extent to which $\mathrm{CPB}$ contributes to morbidity and death. An earlier report from our institution evaluated the effect of $\mathrm{CPB}$ on singlelung, double-lung, and heart-lung recipients. This study included 38 sequential double-lung transplantations, of which 18 required CPB. Analysis of this group showed an adverse effect of CPB on early allograft function and significantly lower patient survival at 1 month. ${ }^{6}$ Similar findings were reported by Egan and associates ${ }^{15}$ in 44 patients who under- 


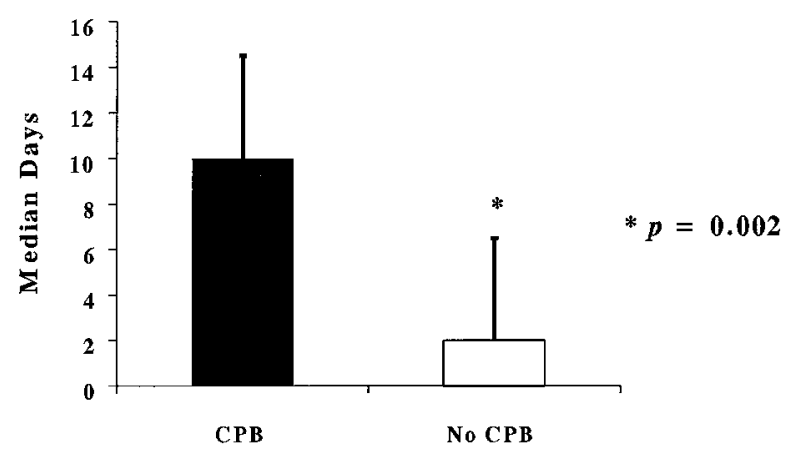

Fig. 4. Duration of intubation. Values are expressed as median \pm standard error of the mean.

went double-lung transplantation for cystic fibrosis. In contrast, Triantafillou and associates ${ }^{16}$ reported no adverse effects of CPB on length of intubation, duration of stay in the intensive care unit, and postoperative oxygenation among sequential double-lung recipients. Others have stated that only prolonged duration of $\mathrm{CPB}$, and not the use of $\mathrm{CPB}$ per se, is detrimental to patient outcome. ${ }^{17}$

Excluding recipients with pulmonary hypertension, where we continue to believe that CPB is mandatory to prevent acute right ventricular failure, bypass was avoided in most patients who underwent double-lung transplantation. In fact, excluding enbloc transplantations $(n=6)$ and pulmonary hypertensives $(n=23)$ (Table III), of 65 patients "at risk" in this series for CPB, only $8(12.3 \%)$ required CPB. This compares favorably with previous reports: the Washington University group used bypass in 18 of $68(26 \%)$ double-lung transplantations performed with the sequential single-lung technique, ${ }^{16}$ and the Toronto group used CPB in 10 of 31 (32\%) patients who underwent double-lung transplantations. ${ }^{18}$

In most of the recipients in this series, the need for CPB was obvious early in the case. By far the most common scenario (5 of 8 patients) was hypotension and hypoxemia during one-lung ventilation instituted to facilitate contralateral hilar dissection. In only one case did hemodynamic instability appear after implantation of the first graft and crossclamping of the second main pulmonary artery; diversion of the entire blood flow through the newly implanted allograft produced acute right heart failure. This is also somewhat different from previously reported experiences. In one series, ${ }^{16}$ very few patients were supported by CPB during implantation of the first allograft; the most common situation requiring support was among those 11 of 18 (61\%)
Table V. Significant risk factors for prolonged posttransplantation intubation ( $>7$ days)

\begin{tabular}{lcc}
\hline \multicolumn{1}{c}{ Risk factor } & $p$ Value & Odds ratio \\
\hline Use of CPB & 0.0004 & 6.2 \\
Recipient diagnosis: & & \\
$\quad$ Pulmonary hypertension & NS & \\
Chronic obstructive pulmonary & NS & \\
$\quad$ disease & & \\
Cystic fibrosis & NS & \\
Pulmonary fibrosis & NS & \\
$\quad$ Bronchiectasis & 0.02 & 5.9 \\
Allograft ischemic time & NS & \\
Year of operation & 0.03 & - \\
Recipient age & 0.06 & $2.0($ age $>35)$ \\
Recipient sex & NS & \\
Donor age & NS & \\
\hline
\end{tabular}

NS, Not significant.

patients who became unstable when complete pulmonary perfusion was routed to the newly implanted lung. The Toronto group reported equal need for CPB both before and after implantation of the first graft. ${ }^{18}$

With so few double-lung transplant recipients (excluding those with pulmonary hypertension) in our series requiring $\mathrm{CPB}$, it was difficult to identify factors that could predict in advance the need for extracorporeal support. Among the patients in this series, none with emphysema needed bypass ( 0 of 11 ), and only 3 of 41 (7\%) recipients with cystic fibrosis needed support. Although few in number, bronchiectasis made up a significant proportion of the group requiring $\mathrm{CPB}$ and may be a risk factor for its use; three of nine $(33 \%)$ patients with this diagnosis were in the $\mathrm{CPB}$ group.

We continue to believe that, when possible, CPB should be avoided; analysis of perioperative events and assessment of early postoperative allograft function in this large series of patients supports this contention. Use of CPB prolonged mean allograft ischemic time for the $\mathrm{CPB}$ group by over 30 minutes and increased the mean requirement for perioperative blood transfusions by 5.4 units. By multiple measurements, CPB had a strong negative impact on early allograft function. Chest $\mathrm{x}$-ray scores at 0 and 24 hours after the operation were significantly worse in the CPB group. Indices of oxygenation at 12 and 24 hours after operation in the CPB group were also well below those in the no-CPB group, and there was a markedly greater incidence of histologically proven DAD among those in the CPB group. Clinical indicators of impaired allograft function also support the conclusion that CPB is deleterious. 
Median length of intubation was a brief 2 days in the no-CPB group, in sharp contrast to a median 10 days in the CPB group. Length of stay in the intensive care unit was 8.5 and 16 days, respectively. The CPB group had a threefold increased requirement for immediate postoperative ECLS.

It is clear that the compositions of the $\mathrm{CPB}$ and no-CPB groups were markedly different with regard to diagnosis. Mandatory use of CPB in all patients with pulmonary hypertension heavily weighted the CPB group with these patients. To assure ourselves that the observed negative effects of CPB were not simply due to CPB acting as a surrogate variable, we performed multivariate logistic regression analysis and examined the roles of multiple variables (including the use of $\mathrm{CPB}$ ) on both the need for prolonged ( $>7$ days) ventilation and 1-month mortality. The results of this analysis demonstrated that $\mathrm{CPB}$ was the strongest independent predictor of the need for prolonged intubation (odds ratio 6.2). A diagnosis of pulmonary hypertension alone did not emerge as an independent predictor of early allograft dysfunction. Other predictors that were found to be significant included a diagnosis of bronchiectasis (odds ratio 5.9), increased recipient age, and earlier year of operation (Table V). Similar analysis confirmed our observation that CPB was not associated with increased 1-month mortality. This suggests that use of CPB is associated with a profound but largely reversible negative effect on the pulmonary graft after transplantation. As a final analysis, we examined the subset of eight patients that required CPB but who did not have pulmonary hypertension. All measures of graft function in this group were remarkably similar to the remainder of the $\mathrm{CPB}$ group and substantially poorer than the noCPB group.

In summary, in the absence of pulmonary hypertension, CPB is only occasionally necessary in double-lung transplantation. In our hands, bypass is associated with substantial early allograft dysfunction after transplantation.

We thank Mr. Wayne Grgurich for his expert work with the University of Pittsburgh Lung Transplant Database.

\section{REFERENCES}

1. Reitz BA, Wallwork JL, Hunt SA, et al. Heart-lung transplantation: successful therapy for patients with pulmonary vascular disease. N Engl J Med 1982;306:551-64.

2. Griffith BP, Hardesty RL, Armitage JM, et al. A decade of lung transplantation. Ann Surg 1993;218:310-20.

3. Griffith BP, Magee MJ, Gonzalez IF, et al. Anastomotic pitfalls in lung transplantation. $\mathrm{J}$ Thorac Cardiovasc Surg 1994;107:743-53.

4. Pasque MK, Kaiser LR, Dresler CM, Trulock EP, Triantafillou A, Cooper JD. Single lung transplantation for pulmonary hypertension: technical aspects and imediate hemodynamic results. J Thorac Cardiovasc Surg 1992;103:475-82.

5. Francalancia NA, Aeba R, Yousem SA, Griffith BP, Marrone GC. Deleterious effects of cardiopulmonary bypass on early graft function after single lung transplantation: evaluation of a heparin-coated circuit. J Heart Lung Transplant 1994;13: 498-507.

6. Aeba R, Griffith BP, Kormos RL, et al. Effect of cardiopulmonary bypass on early graft dysfunction in clinical lung transplantation. Ann Thorac Surg 1994;57;715-22.

7. Zenati M, Dowling RD, Armitage JM, et al. Organ procurement for lung transplantation. Ann Thorac Surg 1989;48: 882-6.

8. Griffith BP, Zenati M. The pulmonary donor. Clin Chest Med 1990;11:217-26.

9. Kawai A, Paradis IL, Keenan RJ, et al. Lung transplantation at the University of Pittsburgh: 1982 to 1994. In: Terasaki PI, Cecka, editors. Clinical transplants 1994. Los Angeles: UCLA Tissue Typing Laboratory; 1994. p. 111-20.

10. Hardesty RL, Aeba R, Armitage JM, Kormos RL, Griffith BP. A clinical trial of University of Wisconsin solution for pulmonary preservation. J Thorac Cardiovasc Surg 1993;105: 660-6.

11. Peris LV, Boix JH, Salom JV, Valentin V, Garcia D, Arnau A. Clinical use of the arterial/alveolar oxygen tension ratio. Crit Care Med 1983;11:888-91.

12. Butler J, Rocker GM, Westaby S. Inflammatory response to cardiopulmonary bypass. Ann Thorac Surg 1993;55:552-9.

13. Downing SW, Edmunds LH. Release of vasoactive substances during cardiopulmonary bypass. Ann Thorac Surg 1992;54:1236-43.

14. Royston D. Blood cell activation. Semin Thorac Cardiovasc Surg 1990;2:341-57.

15. Egan TM, Detterbeck FC, Mill MR, et al. Improved results of lung transplantation for patients with cystic fibrosis. J Thorac Cardiovasc Surg 1995;109:224-35.

16. Triantafillou AN, Pasque MK, Huddleston CB, et al. Predictors, frequency, and indications for cardiopulmonary bypass during lung transplantation in adults. Ann Thorac Surg 1994;57:1248-51.

17. Shennib H, Noirclerc M, Ernst P, et al. Double-lung transplantation for cystic fibrosis. Ann Thorac Surg 1992;54:27-32.

18. de Hoyos A, Demajo W, Snell G, et al. Preoperative prediction for the use of cardiopulmonary bypass in lung transplantation. J Thorac Cardiovasc Surg 1993;106:787-96.

\section{Discussion}

Dr. Frederick L. Grover (Denver, Colo.). The problems associated with having to use CPB during lung transplantation are generally accepted but not very frequently quantified as the authors have so nicely done. Dr. Dave Fullerton and our group demonstrated that using bypass during experimental lung transplantation significantly impairs both the endothelium-dependent and endotheliumindependent relaxation of pulmonary vasculature and thus contributes to a significantly higher pulmonary vascular resistance in the transplanted lung. Other investigators 
have shown increased pulmonary endothelial permeability associated with CPB and activation of complement, leukocytes, and cytokines, all of which can increase the likelihood of damage in the newly transplanted lung during this period of vulnerable reperfusion.

In the Pittsburgh series, CPB was used in only 8 of the $65(12.3 \%)$ nonpulmonary hypertensive or double-lung en-bloc patients. I believe this is one of the most important points of this paper, that is, with the exception of the pulmonary hypertension group, $\mathrm{CPB}$ is usually not required in bilateral sequential lung transplantation, particularly in the hands of an experienced group of surgeons and anesthesiologists.

Dr. Gammie and his associates found several indicators of decreased graft function in the CPB group, and they also found that when possible factors leading to prolonged intubation were analyzed using a multiple logistic regression model, the strongest risk factor was the use of $\mathrm{CPB}$ followed by a diagnosis of bronchiectasis.

I reviewed in brief our experience at the University of Colorado to see whether we had a similar experience in over 70 lung transplantations, 22 of which have been double sequential without pulmonary hypertension. In our experience only four have been supported with $\mathrm{CPB}$, a rate of $18 \%$, which is very similar to the authors'. Our $\mathrm{PaO}_{2} / \mathrm{FiO}_{2}$ ratios also were decreased in the CPB group, very similar to yours, in the early period. However, in variation with your experience, we experienced no major differences in early and late outcome, with our very small group of CPB patients being extubated in 24 to 48 hours.

I have two questions. First, could there be other patient characteristics that were not entered into your logistic regression model that could also have a significant impact on prolonged intubation and outcome, such as serum albumin, weight loss, cachexia, preoperative debilitation, that may have contributed to having to use CPB? In other words, were the patients who had CPB sicker and therefore less likely to do well independent of whether they were supported by bypass?

Dr. Gammie. Dr. Grover, we did not look at indicators of preoperative nutritional status. Our model did include diagnosis, donor and recipient characteristics, and operative factors that have previously been shown to be important in outcome in this group of patients.

We have benefited from a strong institutional experience with lung transplantation and are fortunate to have expert anesthesia colleagues. They are often able to avoid using bypass for these patients by accepting rather severe degrees of hypercarbia with a $\mathrm{Pco}_{2}$ of nearly $100 \mathrm{~mm} \mathrm{Hg}$, provided that there is no ongoing hypoxemia, and they also are fairly aggressive in their use of vasoconstrictors and inotropic agents.

Dr. Grover. My last question relates to your average bypass time of approximately 4 hours, which seems long. Could it be that the variation in your results and ours is perhaps related to the length of bypass as much as to bypass itself?

Dr. Gammie. That could be.

Dr. Joseph Bavaria (Philadelphia, Pa.). Correct me if I'm wrong. Was it one patient that you had who needed to be converted to bypass after the first lung was placed?
Dr. Gammie. That's correct.

Dr. Bavaria. In my experience that's an absolute disaster; we have never had a single patient survive. I just wonder, did that patient survive or not? Do you remember?

Dr. Gammie. That patient did indeed experience a rocky postoperative course, requiring ECMO for 13 days and over a month of ventilatory support. She ultimately survived and is doing well today.

Dr. Bavaria. That is usually a significant primary graft dysfunction problem, and the outcome of that patient probably has nothing to do with CPB or no CPB.

Dr. Douglas Wood (Seattle, Wash.). One question for you. It is clear in all of our minds that CPB may negatively affect the graft as it is going in. Though I am not sure that your results support that conclusion, I think we certainly may agree that is the result. Unfortunately, you have a select group of patients, a sicker group of patients, who are undergoing and requiring CPB than those who are not; it would be nice to have a prospective study in which this is randomized because there are potential advantages to using $\mathrm{CPB}$ as well. One of these, in contrast to your experience, is that our graft ischemia time is less when we are using $\mathrm{CPB}$. We will often have both lungs out before the donor lungs arrive, so we shorten the time of recipient pneumonectomies. There may be an advantage in decreasing the cross-contamination, particularly in the patient with cystic fibrosis or bronchiectasis, in having both lungs out and the field clean before starting implantation. Have you considered any of these effects or the negative impact on the first transplanted lung of reperfusion with the total cardiac output in cases without CPB?

Dr. Gammie. In answer to the last segment of your question first, we did look at the differential radiographic appearances of the first and second implanted lungs and did not find a significant difference in either the CPB or no-CPB groups. Allograft ischemic time did not fall out as a predictor of allograft dysfunction in our multiple regression analysis. The use of CPB was identified as having the single strongest independent effect on early graft dysfunction. These data would not support a randomized study of $\mathrm{CPB}$ but rather suggest that $\mathrm{CPB}$ should be avoided in the routine situation.

Dr. Robert C. Robbins (Stanford, Calif.). I agree with Dr. Bavaria's comment, and you have answered a couple of questions concerning the reperfusion injury to the one lung that has the shorter ischemic time while you are doing the second lung. I think that Dr. Grover's point that your bypass times were quite long does have something to do with your results.

Something that I have started doing is putting the first lung in, then putting the patient on bypass to remove the second lung and implant the second allograft. With this approach the bypass times are certainly shorter. The right lung is protected from high-pressure reperfusion injury during the time the left lung is being implanted. I also think it provides better exposure.

My question is, what about airway complications? Were there any differences in airway complication, such as stenoses in either of these groups?

Dr. Gammie. We did not examine that. 
Dr. Robbins. What about in practice? Do you recall using stents in any patients? I know you might not have looked at it specifically, but my impression is that, if you do not use bypass, the left lung tends to be a little bit tougher to expose, especially in the patients with cystic fibrosis. My point is that if you put the right lung in then you can use a short period of bypass to facilitate your exposure for left lung implantation. This may also lessen the injury to the right lung.

Dr. Gammie. My impression is that the airway anastomotic complications have been fairly evenly distributed between the CPB and no-CPB groups.

Dr. Paul Waters (Los Angeles, Calif.). I agree with your conclusions. I think putting the patient on bypass adds to their possible morbidity, but I wonder if grouping the primary pulmonary hypertension patients and the few patients you had who had emphysema and the larger number of patients with bronchiectasis and cystic fibrosis are basically the same thing when you are performing a transplantation; the cause is different. I wonder whether it is appropriate to bunch those two groups together. Patients with pulmonary hypertension are completely different in the postoperative phase. The condition tends to be very difficult to manage. These patients tend to have more allograft dysfunction; I wonder if you look at those groups separately what your conclusions might be.

Dr. Gammie. That is a good question; actually we did look at those eight patients who were nonpulmonary hypertensive and who were on bypass, and it was really remarkable. All measures of outcome in that group were virtually identical to the rest of the pulmonary hypertension group. They required 18 units of blood. They were intubated for a median 18 days, so I think that lends some support to our hypothesis.

Dr. Waters. But you also had 38 or 28 patients with cystic fibrosis?

Dr. Gammie. Thirty-eight of 41 recipients with cystic fibrosis were operated on without CPB.

Dr. Waters. That is a lot of patients, and I am sure the blood loss, just as an example, would be quite a bit more in those patients while on bypass than the pulmonary hypertensive patients who usually do not have a fused pleural cavity.

Dr. Gammie. Our multiple regression analysis demonstrates that the diagnosis of cystic fibrosis did not have an independent negative impact on early graft function, whereas $\mathrm{CPB}$ clearly did.

\section{Bound volumes available to subscribers}

Bound volumes of The Journal of Thoracic and Cardiovascular Surgery are available to subscribers (only) for the 1998 issues from the Publisher, at a cost of $\$ 122.00$ for domestic, $\$ 151.94$ for Canadian, and $\$ 142.00$ for international subscribers for Vol. 115 (January-June) and Vol. 116 (July-December). Shipping charges are included. Each bound volume contains a subject and author index and all advertising is removed. Copies are shipped within 60 days after publication of the last issue of the volume. The binding is durable buckram with the Journal name, volume number, and year stamped in gold on the spine. Payment must accompany all orders. Contact Mosby, Inc., Subscription Services, 11830 Westline Industrial Drive, St. Louis, Missouri 63146-3318, USA; phone $800-453-4351$ or $314-453-4351$.

Subscriptions must be in force to qualify. Bound volumes are not available in place of a regular Journal subscription. 